\title{
Chiari malformation type 1 with scoliosis: A case report
}

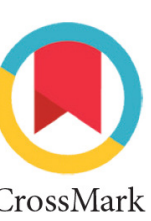

\author{
Rudy Gunawan ${ }^{1 *}$, Novan Krisno Adji ${ }^{1}$, Nastiti Widoretno ${ }^{1}$
}

\section{ABSTRACT}

Introduction: Chiari type 1 malformation associate with some abnormalities of the spinal cord and spine. Suboccipital decompression to prevent progression or deterioration scoliosis are still differences concern.

Case presentation: $\mathrm{A} 39$ years old Madurese woman comes with an occipital headache for 5 years and getting worse. The patient is a housewife from rural and agricultural one of the Jember area. There are also sensory deficits like extreme pain in neck, shoulder, arms, and legs, numbness in hands and feet, unable to feel hot and cold. Motoric deficit like weakness, stiffness, loss of fine motor control, balance problem, and other symptoms like loss of vision oculi dextra and otalgia dextra. Patients have no history of previous illnesses such as spinal injury, diabetes mellitus, heart disease, asthma, high blood pressure, and no family history has a similar complaint. Thorax photo showed dextroscoliosis, no spinal deformity, no kyphosis. Cervical MRI showed cerebellar herniation. Neurosurgeon considers performing suboccipital decompression. Two months post-operative all symptoms slowly decreased.

Conclusion: Chiari type 1 could be associate with scoliosis and suboccipital decompression could relieve the symptoms.

Keywords: Chiari malformation type I, scoliosis, suboccipital decompression

Cite This Article: Gunawan, R., Adji, N.K., Widoretno, N. 2020. Chiari malformation type 1 with scoliosis: A case report. Indonesian Journal of Neurosurgery 3(2): 59-62. DOI: 10.15562/ijn.v3i2.75

'Department of Neurosurgery, Faculty of Medicine, Universitas Jember, Soebandi General Hospital, Jember, Indonesia
*Corresponding author: Rudy Gunawan; Department of Neurosurgery, Faculty of Medicine, Universitas Jember, Soebandi General Hospital, Jember, Indonesia;

rudygunawan10@gmail.com

Received: 2019-07-19

Accepted: 2019-10-10

Published: 2020-08-01

\section{INTRODUCTION}

Chiari type 1 malformation is associated with some abnormalities of the spinal cord and spine. Some problem could cause Chiari malformation including thickening of ligamentum flavum, retroflexion of the odontoid process, atlantoaxial assimilation, and Klippel-Feil deformity. ${ }^{1}$

The incidence of idiopathic scoliosis with brainstem or spinal cord abnormalities ranges to $58 \%$. To prevent the potential risk of neurologic complication, we need to address the cause of these lesions before undertaking treatment. ${ }^{2}$ Numerous Chiari type 1 malformation could cause scoliosis in up to $20 \%$ of patients. ${ }^{3}$

Chiari I malformation (CMI) is defined as herniation of cerebellar tonsils below the level of the foramen magnum to the upper cervical canal. This condition is commonly associated with skull abnormally of small posterior fossa. ${ }^{4}$ Scoliosis has been defined as a $10^{\circ}$ deviation of the lateral curve of the spine (cervical, thoracic, lumbar, thoracolumbar) as measured by Cobb angles with vertebral rotation on a standing upright radiograph of the spine. ${ }^{2}$

Before correct scoliosis, most of neurosurgeons consider suboccipital decompression to prevent acute neurological deterioration impaction of the cerebellar tonsils intra and post-operative although there are still different concerns for this treatment. ${ }^{1}$ In this study, we aim to report Chiari malformation type 1 with scoliosis.

\section{CASE PRESENTATION}

A 39 years old Madurese woman comes with an occipital headache for 5 years and getting worse, the patient is a housewife from rural and agricultural one of the Jember area. There are also sensory deficits like extreme pain in neck, shoulder, arms, and legs, numbness in hands and feet, unable to feel hot and cold. Motoric deficit like weakness, stiffness, loss of fine motor control, balance problem, and other symptoms like loss of vision oculi dextra and otalgia dextra. Patients have never got similar complaints before, so far the patient has never examined his health, and take regular pain medication if symptoms were recurrent, but recently the occipital headache getting worse and does not affect with pain medication. Patients have no history of previous illnesses such as spinal injury, diabetes mellitus, heart disease, asthma, high blood pressure, and no family history has a similar complaint.

Neurosurgeon decided cervical MRI find an abnormality. MRI showed herniation of cerebellar 


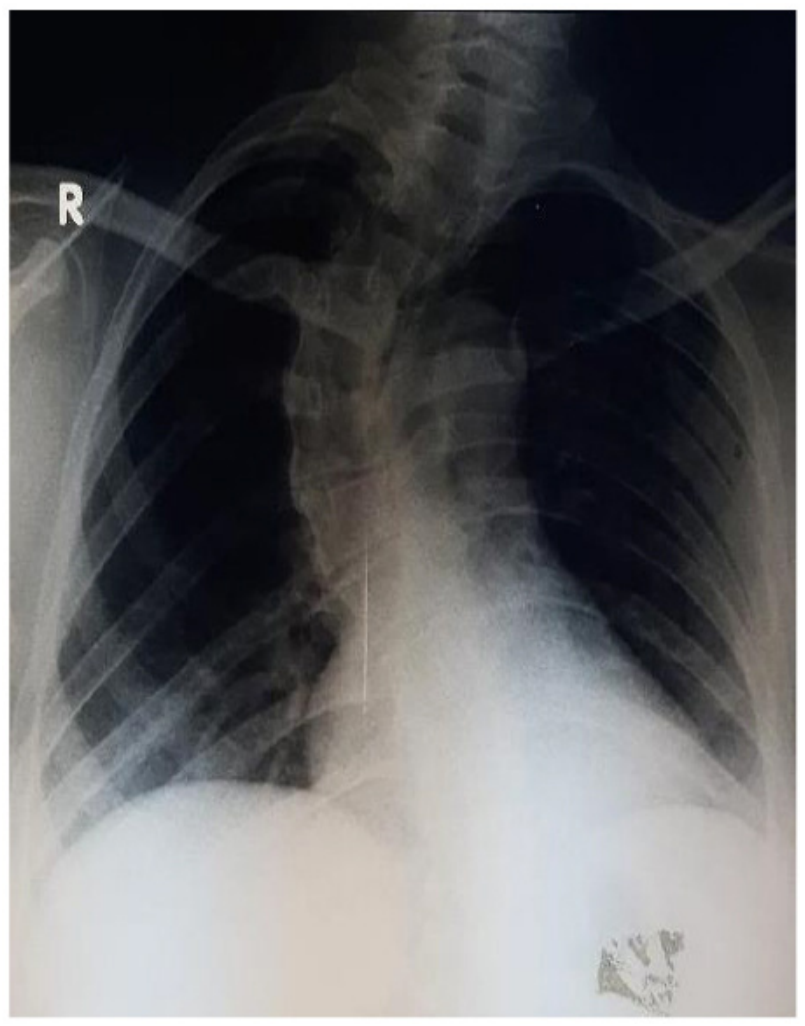

Figure 1. Thorax photo shows dextroscoliosis, no spinal deformity, and no kyphosis.

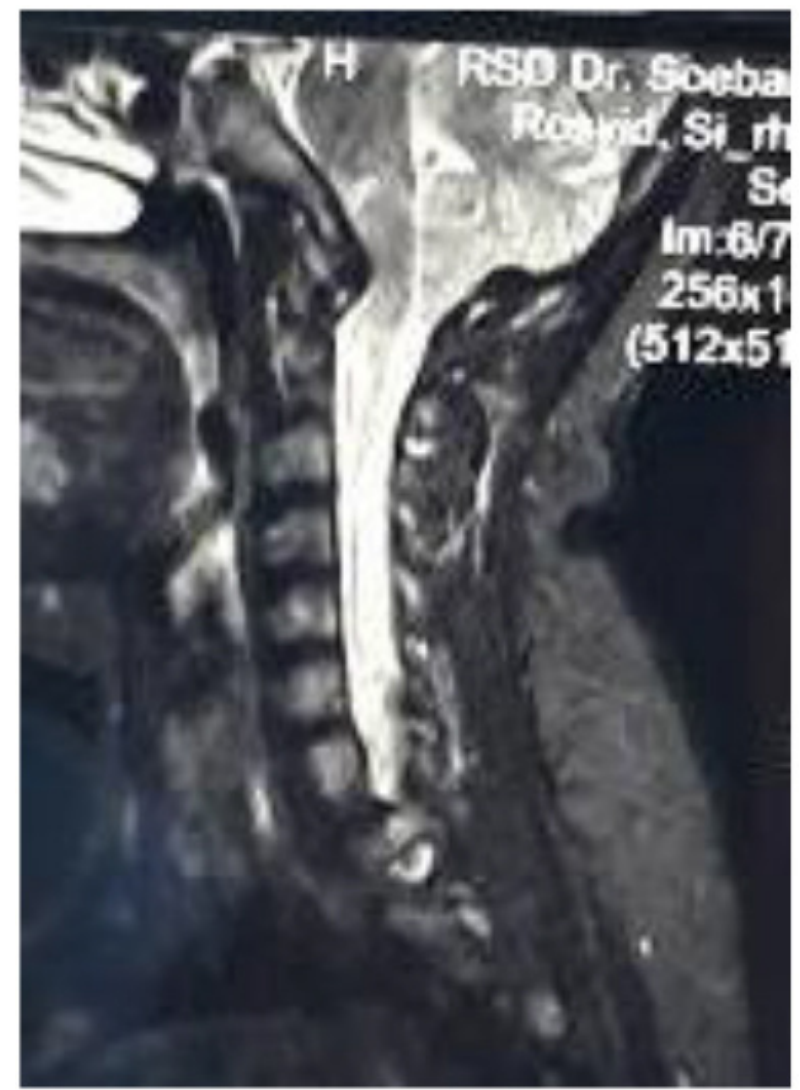

Figure 2. T1 STIR sagittal cervical MRI showed cerebellar herniation. tonsils below the level of the foramen magnum to the upper cervical canal. Then, neurosurgeon planned to perform suboccipital decompression. Two months post-operative all symptoms slowly decreased. Our limitation is we did not measure the cobb angle pre and post suboccipital decompression.

\section{DISCUSSION}

Scoliosis has been defined as a $10^{\circ}$ deviation of the lateral curve of the spine (cervical, thoracic, lumbar, thoracolumbar) as measured by Cobb angles with vertebral rotation on a standing upright radiograph of the spine. Scoliosis is commonly found in children and adolescents, often with no cause readily present. ${ }^{2,6}$ Adolescence idiopathic scoliosis (AIS) is a common problem affecting $4 \%$ of 10-16 years old. Progression and deterioration of scoliosis can be associated with serious neurological problems, such as Chiari. ${ }^{7}$

The researchers decided to focus on six characteristics to be atypical in scoliosis patients: ${ }^{8}$ 1) Early-onset, before the age of 10 years old, 2) Atypical curve pattern, a single left thoracic curve is one such example, 3) Severe curves despite immaturity, defined as a Cobb angle of greater than 45 degrees, 4) Rapid curve progression, defined as an increase in curvature of more than 1 degree per month, 5) Abnormal neurological changes, such as altered or absent reflexes, and 6) Chronic disturbing back pain or headache

The pathophysiology of the spinal abnormality caused by Chiari malformation type 1 was poorly understood. Some researchers argued that anterior horn cell dysfunction affected by the formation of a syrinx by scoliosis. But, other researchers say that cerebellar tonsil compression cause scoliosis. ${ }^{9}$ Patients with Chiari malformation have atypical clinical manifestation findings, a left atypical curve, kyphotic deformity associated with the curve, such as neurological deficit or early onset. ${ }^{10}$

Huebert and Mackinnon say that scoliosis caused by syringomyelia danger cells in the spinal cord that is responsible for muscle balance of the trunk. Suboccipital decompression of Chiari malformation has been shown to improve neurologic function. Improvement neurologic function cause improvement of scoliosis if decompression early enough is undertaken before permanent damage occur. ${ }^{2}$

The relationship between Chiari, syringomyelia, and scoliosis is complex and poorly understood. MRIs have shown that numerous idiopathic scoliosis involves Chiari or syringomyelia. Recently, researchers and clinicians should get MRI for scoliosis patients to look for Chiari. Treating the underlying Chiari or syringomyelia can stop 


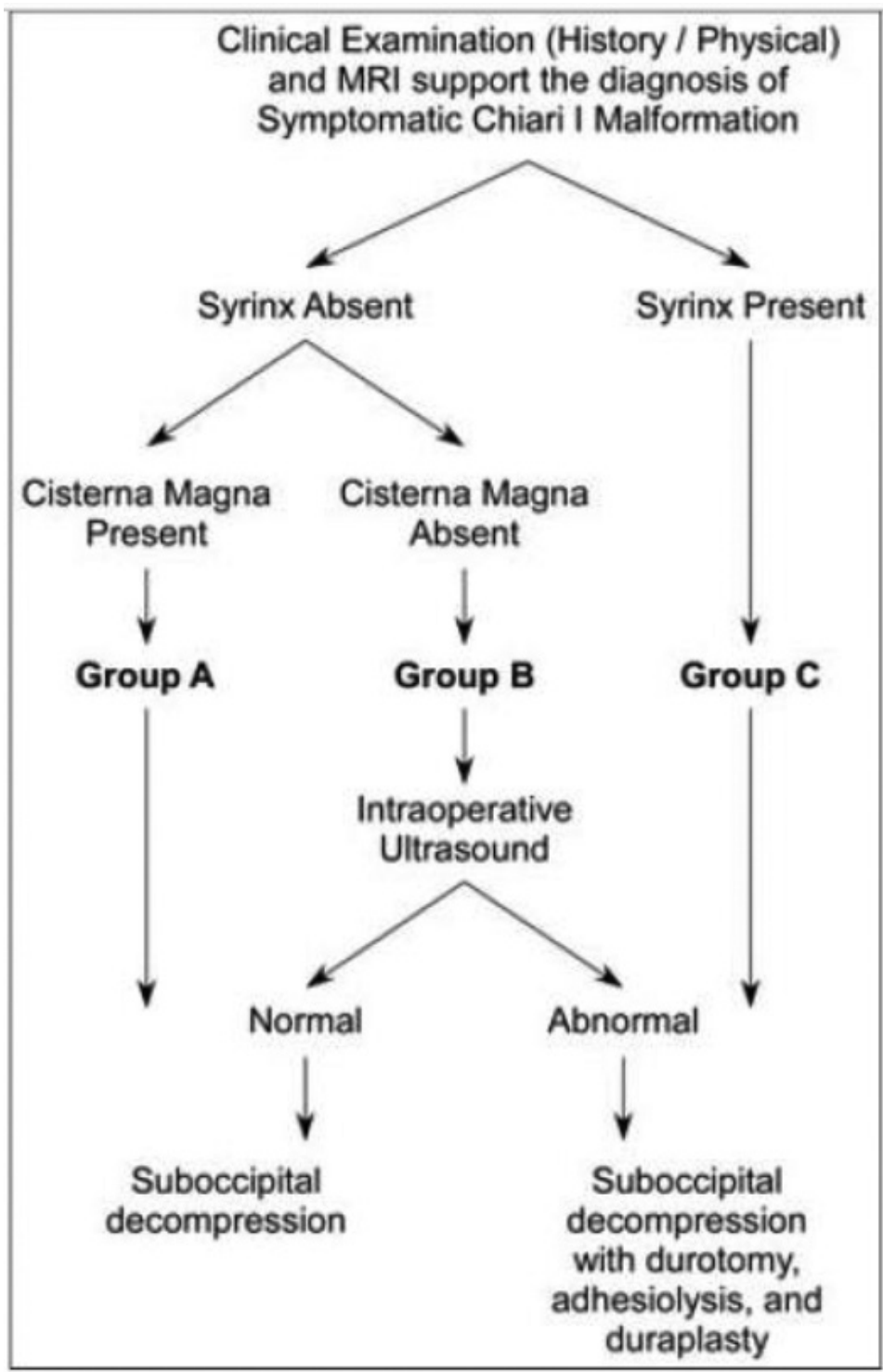

Figure 3. Classification of surgical procedure on Chiari malformation

the progression of scoliosis. Performing correct scoliosis without first treating an active syrinx can be very risky. Some studies have shown that up to $1 / 3$ of such surgeries can lead to deterioration or progression of neurological problems. ${ }^{11}$ This has led many neurosurgeons to consider that in cases Chiari with scoliosis to treat the Chiari first, then address scoliosis if it does not improve. ${ }^{1}$

This study support previous research that the younger age undertaken corrected scoliosis surgery the less severe scoliosis is. The progression of spinal curvature associated with Chiari at a young age seems critical to arresting. The neurosurgeon has to establish guidelines and criteria when an MRI should be performed when a child develops scoliosis. Early diagnosis will certainly improve the outcome of children with Chiari malformation. ${ }^{11}$
There are two major therapies for Chiari malformation, surgical therapy for symptomatic patients whose main goal is suboccipital decompression and non-surgical therapy to relieve neuropathic pain. ${ }^{4}$ In this case, we did suboccipital decompression to minimize the symptom, especially sensory and motoric dysfunction. Two months post-operative all symptoms slowly decrease.

\section{CONCLUSION}

Chiari type 1 could be associate with scoliosis and suboccipital decompression could relieve the symptoms.

\section{CONFLICT OF INTEREST}

None of the conflicts of interest in this study.

\section{FUNDING}

None of the specific funding.

\section{AUTHORS' CONTRIBUTIONS}

All authors took part in the design, data collection, and manuscript writing of the study.

\section{REFERENCES:}

1. Bhangoo R, Sgouros S. Scoliosis in children with Chiari I-related syringomyelia. Childs Nerv Syst. 2006; 22(9): 1154 - 1157. DOI: 10.1007/s00381-006-0090-y.

2. Eule JM, Erickson MA, O’Brien MF, Handler M. Chiari I malformation associated with syringomyelia and scoliosis: A twenty-year review of surgical and nonsurgical treatment in a pediatric population. Spine (Phila Pa 1976). 2002; 27(13): 1451 - 1455. DOI: 10.1097/00007632-20020701000015.

3. Kelly MP, Guilaume TJ, Lenke LG. Spinal deformity associated with Chiari malformation. Neurosurg Clin N Am. 2015; 26(4): 579 - 585. DOI: 10.1016/j.nec.2015.06.005.

4. Zhang ZQ, Chen YQ, Chen YA, Wu X, Wang YB, Li XG. Chiari I malformation associated with syringomyelia: A retrospective study of 316 surgically treated patients. Spinal Cord. 2008; 46(5): 358 - 363. DOI: 10.1038/sj.sc.3102141.

5. Qiu Y, Zhu Z, Wang B, Yu Y, Qian B, Zhu F. Radiological presentations in relation to curve severity in scoliosis associated with syringomyelia. J Pediatr Orthop. 2008; 28(1): 128 - 33. DOI: 10.1097/bpo.0b013e31815ff371.

6. Chu WCW, Man GCW, Lam WWM, Yeung BHY, Chau WW, Ng BKW, et al. A detailed morphologic and functional magnetic resonance imaging study of the craniocervical junction in adolescent idiopathic scoliosis. Spine (Phila Pa 1976). 2007; 32(15): 1667 - 74. DOI: 10.1097/BRS.0b013e318074d539.

7. Morcuende JA, Dolan LA, Vazquez JD, Jirasirakul A, Weinstein SL. A prognostic model for the presence of neurogenic lesions in atypical idiopathic scoliosis. Spine (Phila Pa 1976). 2004; 29(1): 51 - 8. DOI: 10.1097/01. BRS.0000105526.65485.92.

8. Brockmeyer DL. Editorial. Chiari malformation type I and scoliosis: The complexity of curves. J Neurosurg Pediatr. 2011; 7(1): 22 - 3; discussion 23 - 4. DOI: 10.3171/2010.9.PEDS10383. 
9. Hwang SW, Samdani AF, Jea A, Raval A, Gaughan JP, Betz $\mathrm{RR}$, et al. Outcomes of Chiari I-associated scoliosis after intervention: A meta-analysis of the pediatric literature. Childs Nerv Syst. 2012; 28(8): 1213 - 1219. DOI: 10.1007/ s00381-012-1739-3.

10. Inoue $\mathrm{M}$, Minami S, Nakata $\mathrm{Y}$, Otsuka $\mathrm{Y}$, Takaso M, Kitahara $\mathrm{H}$, et al. Preoperative MRI analysis of patients with idiopathic scoliosis: a prospective study. Spine (Phila Pa 1976). 2005 ;30(1): 108 - 14. DOI: 10.1097/01. brs.0000149075.96242.0e.

11. Brockmeyer D, Gollogly S, Smith JT. Scoliosis associated with Chiari I malformations: The effect of suboccipital decompression on scoliosis curve progression: A preliminary study. Spine (Phila Pa 1976). 2003; 28(22): 2505 - 9. DOI: 10.1097/01.BRS.0000092381.05229.87.

12. Shamji MF, Ventureyra ECG, Baronia B, Nzau M, Vassilyadi M. Classification of symptomatic Chiari I malformation to guide surgical strategy. Can J Neurol Sci. 2010; 37(4): 482 7. DOI: $10.1017 / \mathrm{s} 0317167100010507$.

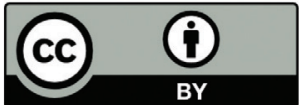

This work is licensed under a Creative Commons Attribution 